\title{
A indeterminação do sujeito na Bahia: a contribuição do ALiB para o ensino
}

\section{The indeterminacy of the subject in Bahia: the contribution of the ALiB to teaching}

\author{
Tassila Ferreira Vale Guimarães ${ }^{1}$ \\ Norma da Silva Lopes ${ }^{2}$
}

Resumo: Este artigo apresenta um estudo que se situa entre a dialetologia e a sociolinguística sobre a variação social e espacial da indeterminação do sujeito no estado da Bahia. A partir de dados coletados do ALiB em sete mesorregiões da Bahia, observam-se condicionamentos sociais e espaciais para a escolha de variantes gramaticais, pronominais e nominais de indeterminação do sujeito. O estudo identifica tendência de desaparecimento de uma forma gramatical (verbo em terceira pessoa sem o se) e um tipo de forma nominal de indeterminação (variantes nominais do grupo C). Além disso, o estudo consegue mapear as áreas de maior uso de formas nominais do grupo A no estado da Bahia (constituídas por artigo + nome). A pesquisa apresenta um material que pode contribuir para o ensino da língua portuguesa, de forma a possibilitar explorar a realidade linguística sem preconceito.

Palavras-Chave: Indeterminação do sujeito; Mesorregiões da Bahia; ALiB; Dialetologia e Sociolinguística.

Abstract: This article presents a study that is positioned between dialecology and sociolinguistics about the social and spatial variation of the indetermination of the subject in the state of Bahia. Based on data collected from the ALiB in seven mesoregions of Bahia, we observe social and spatial conditions for the choice of grammatical, pronominal and nominal variants of indetermination of the subject. The study identifies a tendency to disappear in a grammatical form (third person verb without se) and a type of nominal form of indetermination (nominal variants of group $\mathrm{C}$ ). In addition, the study is able to map the areas of greater use of nominal forms of group A in the state of Bahia. The research presents a material that can contribute to the teaching of the Portuguese language, so as to make it possible to explore the linguistic reality without prejudice.

Keywords: Indeterminacy of the subject; Meso-regions of Bahia; ALiB; Dialectology and Sociolinguistics.

\footnotetext{
${ }^{1}$ Professora da Secretaria da Educação do Estado da Bahia, Mestre egressa do PPGEL/UNEB. Email: tassila.ferreira.vale@gmail.com 2 Professora Plena da Universidade do Estado da Bahia, Permanente do Programa de Pós-Graduação em Estudo de Linguagens (PPGEL/UNEB). Email: nlopes58@gmail.com
} 


\section{Introdução}

Este artigo tem como foco o fenômeno da variação espacial e social da indeterminação do sujeito no estado da Bahia e tem como objetivos fazer um mapeamento das escolhas das variantes de sujeito indeterminado entre as mesorregiões baianas e identificar condicionamentos para a escolha das diferentes estratégias nesse estado. Situa-se, nesse sentido, entre os estudos geossociolinguísticos, fazendo uma interface entre a dialetologia e a sociolinguística,

Os estudos dialetológicos na Bahia têm, na sua história, a realização dos primeiros atlas brasileiros, o Atlas Prévio dos Falares Baianos (APFB) e o Atlas Linguístico de Sergipe (ALS), pelo grupo do professor Nelson Rossi, da Universidade Federal da Bahia (UFBA), nas décadas de 60 e 70, do século XX. E, também na Bahia, nasceu o Atlas Linguístico do Brasil (ALiB), em 1996, durante o Simpósio Caminhos e Perspectivas para a Geolinguística no Brasil, realizado na UFBA. A realização dos inquéritos do ALiB se deu entre os anos de 2001 a 2013, abrangendo 250 pontos do território brasileiro. (CARDOSO et al., 2014)

Este trabalho apresenta resultados de uma pesquisa variacionista, observando dados do ALiB nas sete mesorregiões do estado da Bahia. Busca-se, neste artigo, entender o processo da variação entre as formas de indeterminação do sujeito no estado da Bahia, onde o ALiB registrou a fala em 22 pontos.

A figura 1 apresenta o mapa da Bahia com a localização das sete mesorregiões baianas: Extremo Oeste Baiano, Vale São-Franciscano da Bahia, Centro-Sul Baiano, Sul Baiano, Centro-Norte Baiano, Nordeste Baiano, Metropolitana de Salvador. Os informantes analisados nesta pesquisa perfazem um total de 28 e são distribuídos de acordo com a localidade, sexo e faixa etária. Como apenas nas capitais foram entrevistados falantes de nível superior, a escolaridade selecionada para a presente pesquisa foi apenas o nível fundamental, contemplada em todos os pontos do atlas, seja capital. seja interior.

Figura 1: Mesorregiões da Bahia

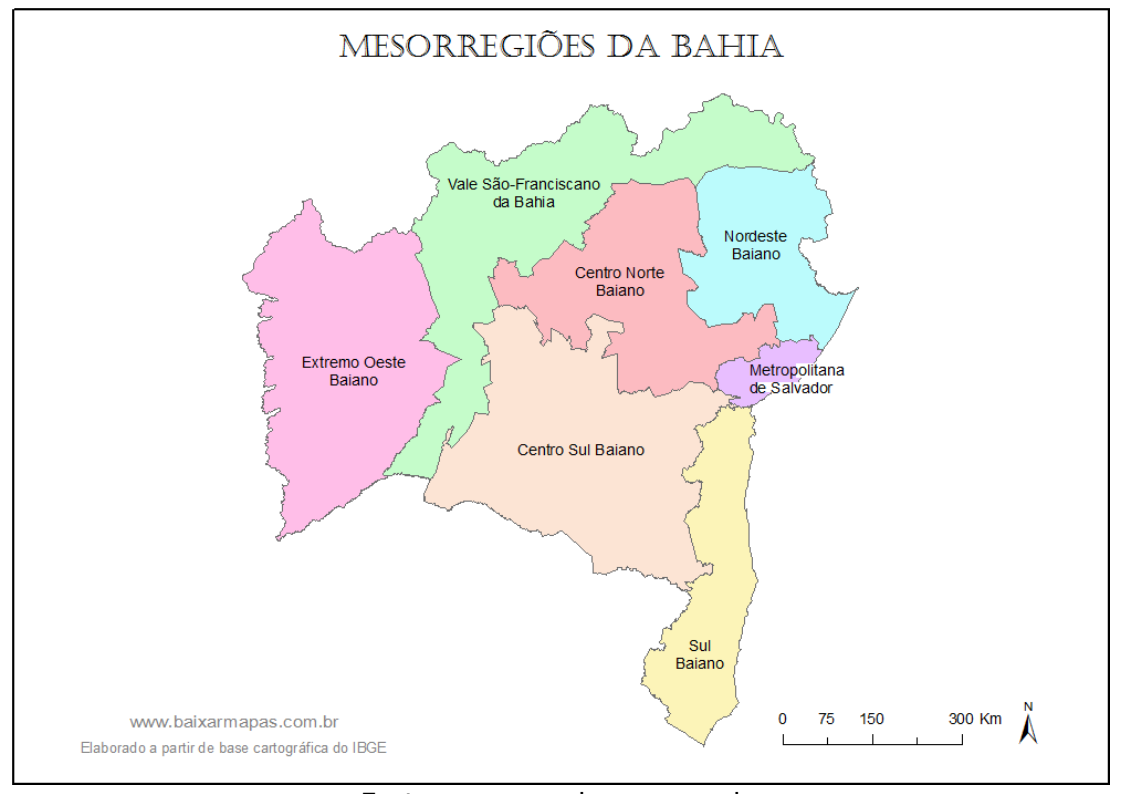

Fonte: www.googlemaps.com.br

Este arquivo se divide nas seguintes seções: na $1^{\text {a }}$, se faz um rápido panorama de como é tratado o tema nas gramáticas normativas e apresentam-se alguns resultados de estudos linguísticos 
sobre o fenômeno; em seguida, define-se o envelope da variação, com a variável dependente, as variantes, e as variáveis independentes; na 3a. seção, faz-se a análise dos dados e apresentam-se os resultados. Finalmente, são feitas as Considerações Finais e as Referências. Dizer como o artigo está estruturado

\section{A indeterminação do sujeito na tradição gramatical e em pesquisas linguísticas}

Rocha Lima (1985, p.206) conceitua sujeito indeterminado como aquele que não é possível ou não se quer identificar, trazendo apenas duas possíveis formas de indeterminação: "1. empregar o verbo na $3^{a}$ pessoa do plural (1); 2. usá-lo na terceira pessoa do singular acompanhado da partícula SE" (2). Quanto à segunda forma, Rocha Lima (1985, p.206) acrescenta que o verbo na terceira pessoa do singular deve ser intransitivo ou apresentar complemento preposicional.

(1) Mataram um guarda. ${ }^{3}$

(2) Precisa-se de professores.

Cunha e Cintra (1985, p.125), na segunda edição da Nova gramática do português contemporâneo, definem sujeito indeterminado como aquele ser desconhecido que executa a ação, ou até mesmo aquele sobre o qual não há o "interesse no seu conhecimento". Os autores trazem as mesmas formas de indeterminação descritas por Rocha Lima (1985), acrescentando apenas que as duas podem ocorrer simultaneamente em um enunciado (3).

(3) Na casa pisavam sem sapatos, e falava-se baixo. ${ }^{4}$

Neves (2000) afirma que o sujeito pode ser semanticamente indeterminado, ainda que lexicalmente marcado, o que a gramática tradicional (GT) chamaria comumente de sujeito simples (4).

(4) Você vai lá, fica dois dias fazendo curso, eles te catequizam, fazem você comprar uma tonelada de sabão e abrir o seu negócio. ${ }^{5}$

Perini (2010), na Gramática do português brasileiro, lista os seguintes recursos sintáticos e lexicais para indeterminar o sujeito: sintagma nominal sem determinante (5); verbo na terceira pessoa do plural desacompanhado de sujeito (6); verbo sem sujeito na terceira pessoa do singular (7); uso de determinados itens lexicais (8) e (9); verbo no infinitivo sem sujeito (10). Perini (2010, p. 85) ainda admite, em uma nota de rodapé, que "a construção indeterminada com 'se' é rara no PB".

\footnotetext{
${ }^{3}$ Exemplos (1) e (2) retirados de Rocha Lima (1985, p.206).

${ }^{4}$ Exemplo de Cunha e Cintra (1985, p. 126).

${ }^{5}$ Exemplo de Neves (2000, p. 463).
} 
(5) Criança suja muito o chão. ${ }^{6}$

(6) Quebraram a janela.

(7) Nessa fazenda planta café e milho.

(8) Ou você pertence àquele grupo de críticos ou te ignoram completamente.

(9) $O$ sujeito toma droga e ameaça quebrar tudo.

(10) Nadar é bom para a saúde.

\section{Aspectos Metodológicos}

Para fazer o mapeamento das formas de indeterminação do sujeito, foram ouvidas as entrevistas do acervo ALiB das sete cidades escolhidas das mesorregiões da Bahia. Em cada uma delas, foram levantados dados de sujeito indeterminado de quatro informantes, dois do sexo masculino e dois do sexo feminino, divididos igualmente entre as faixas etárias 1 e 2, o que perfez um total de 28 informantes. No estudo aqui empreendido, consideraram-se as seguintes variantes do sujeito indeterminado, apresentadas no quadro 1.

Quadro 1: Variantes observadas de indeterminação do sujeito.

\begin{tabular}{|c|c|c|}
\hline Tipos & Variantes & Exemplos \\
\hline \multirow[t]{4}{*}{ Gramaticais } & $\begin{array}{l}\text { Verbo na terceira pessoa do singular, } \\
\text { acompanhado da partícula "se" }\end{array}$ & "Se fala que tá clareando," \\
\hline & $\begin{array}{l}\text { Verbo na terceira pessoa do singular, } \\
\text { desacompanhado da partícula "se" }\end{array}$ & "Chama criança também. \\
\hline & Verbo na terceira pessoa do plural ${ }^{7}$ & "Usam muito pra por rapadura." \\
\hline & Infinitivo & "Comprar o terreno, né." \\
\hline \multirow[t]{3}{*}{ Pronominais } & A gente & $\begin{array}{l}\text { "A gente vê mais na época de } \\
\text { São João". }\end{array}$ \\
\hline & Nós & Aqui nós falamos lombada \\
\hline & Você & $\begin{array}{l}\text { Você põe água e o pó pra ficar } \\
\text { branco }\end{array}$ \\
\hline \multirow[t]{3}{*}{ Nominais } & As pessoas & "As pessoas falam trovoada." \\
\hline & Os outros & "Os outros falam trovão." \\
\hline & Fulano & "Fulano é mão de figa." \\
\hline
\end{tabular}

\footnotetext{
${ }^{6}$ Exemplos de (5) a (10 extraídos de Perini (2010, p. 84-85)

7 Conjuntamente com essa variante, também foi considerada variante gramatical essa estrutura com o ELES explicitado, no sentido de qualquer pessoa (indeterminado).
} 
O povo

Uns

Muita gente
"O povo diz assim, a pelada."

"Uns faz de um jeito."

"Muita gente fala assim."

As variáveis independentes controladas são as seguintes:

- Faixa etária:

Faixa etária 1 - de 15 a 30 anos; Faixa etária 2 - de 50 a 65 anos

- Sexo:

Homem; Mulher

- Cidade/Região:

Alagoinhas/Nordeste Baiano; Barra/Vale São-Franciscano da Bahia; Barreiras/Centro-Oeste Baiano; Ilhéus/Sul Baiano; Irecê/Centro-Norte Baiano; Salvador/Região Metropolitana; Vitória da Conquista/Centro-Sul Baiano

Análise dos dados

Como analisar um corpus com tantas variantes de indeterminação? A análise foi feita, inicialmente, dividindo as variantes nos diferentes grupos: formas gramaticais, formas pronominais e formas/sintagmas nominais.

1. Formas gramaticais: $3^{\mathrm{a}}$ pessoa do singular com ou sem $\mathrm{SE}, 3^{\mathrm{a}}$ pessoa do plural, infinitivo

2. Formas pronominais: Nós, a gente, você

3. Formas/sintagmas nominais: o povo, o pessoal, a turma, cada um...

A tabela 1 apresenta, em termos percentuais, os resultados gerais, incluindo os três tipos de variantes, gramaticais, pronominais e sintagmas nominais semanticamente indeterminados nas mesorregiões estudadas. Os resultados apresentados revelam que as formas gramaticais são o tipo de variantes mais utilizado para indeterminar o sujeito, aproximando-se a $50 \%$ dos sujeitos indeterminados.

Tabela 1: Frequência dos três tipos de variantes de indeterminação do sujeito encontrados nas mesorregiões do estado da Bahia

\begin{tabular}{l|l|l}
\hline Variantes & Ocorrências/Total & \\
\hline Formas gramaticais & $403 / 811$ & $49,7 \%$ \\
\hline Formas pronominais & & $17,6 \%$ \\
\hline
\end{tabular}




\begin{tabular}{l|l|l}
\hline Formas nominais & $265 / 811$ & $32,7 \%$ \\
\hline TOTAL & $811 / 811$ & $100 \%$ \\
\hline
\end{tabular}

Em ordem decrescente de frequência, as formas nominais de indeterminação são utilizadas com uma frequência de $32,7 \%$ e, por último, nos dados levantados, são as formas pronominais as menos utilizadas, com um índice de $17,6 \%$ das variantes.

Na seção que se segue, serão apresentados resultados da observação de cada variante dentre as formas gramaticais.

\section{Análise das formas gramaticais}

Dentre as formas gramaticais, a indeterminação do sujeito expressa pelo verbo na terceira pessoa do singular sem o SE ocorreu em $67 \%$ nos dados, muito acima de todas as outras variantes desse grupo. A variante Verbo na terceira pessoa do singular+SE e o Verbo na terceira pessoa do plural, formas previstas pela tradição gramatical, foram registradas em um número percentual bem menor, respectivamente $8 \%$ e $22 \%$. A variante de indeterminação Verbo no infinitivo apresentou somente oito ocorrências, $2 \%$ do total de dados. A tabela 2 apresenta os resultados.

Tabela 2: Frequência das Formas gramaticais de indeterminação nas mesorregiões baianas.

\begin{tabular}{l|l|l}
\hline Variantes /Exemplos & $68 \%$ \\
\hline 3aS-SE - "Chama criança também." & $273 / 403$ & \\
\hline 3apI - "Usam muito pra por rapadura". & $90 / 403$ & $22 \%$ \\
\hline 3aS+ SE - "Se fala que tá clareando, né?" & $32 / 403$ & $8 \%$ \\
\hline INF - "Comprar o terreno, né." & $8 / 403$ & $2 \%$ \\
\hline
\end{tabular}

Para que fosse possível a obtenção de uma oposição binária, com a finalidade de se chegar a uma análise de regras variáveis envolvendo as variantes gramaticais de indeterminação do sujeito, optouse, neste texto, por considerar apenas as variantes mais recorrentes, a Terceira pessoa do singular sem o SE e a Terceira pessoa do plural. Utilizou-se o GoldVarb, programa computacional de regras variáveis. Apesar de serem controladas as variáveis faixa etária, mesorregiões e gênero na análise empreendida, apenas a faixa etária foi selecionada pelo programa quantitativo utilizado. 
Embora os grupos de faixa etária tenham apresentado taxas próximas de uso da variante, a faixa etária 2 demonstrou favorecimento da variante Verbo na terceira pessoa do singular sem o SE (peso relativo .569); essa variante é desfavorecida pela faixa etária 1 , peso relativo .43). As ocorrências, somadas ao estudo dos pesos relativos, revelaram que, enquanto os mais idosos tendem a utilizar a variante de indeterminação Verbo na $3^{a}$ pessoa do Singular sem o SE, os mais jovens desfavorecem o uso dessa forma, demonstrando preferência pela variante Verbo na $3^{a}$ pessoa do plural de indeterminação do sujeito.

O gráfico 1 permite melhor visualização da diferença em pesos relativos do condicionamento da idade na escolha da variante pelos dois grupos.

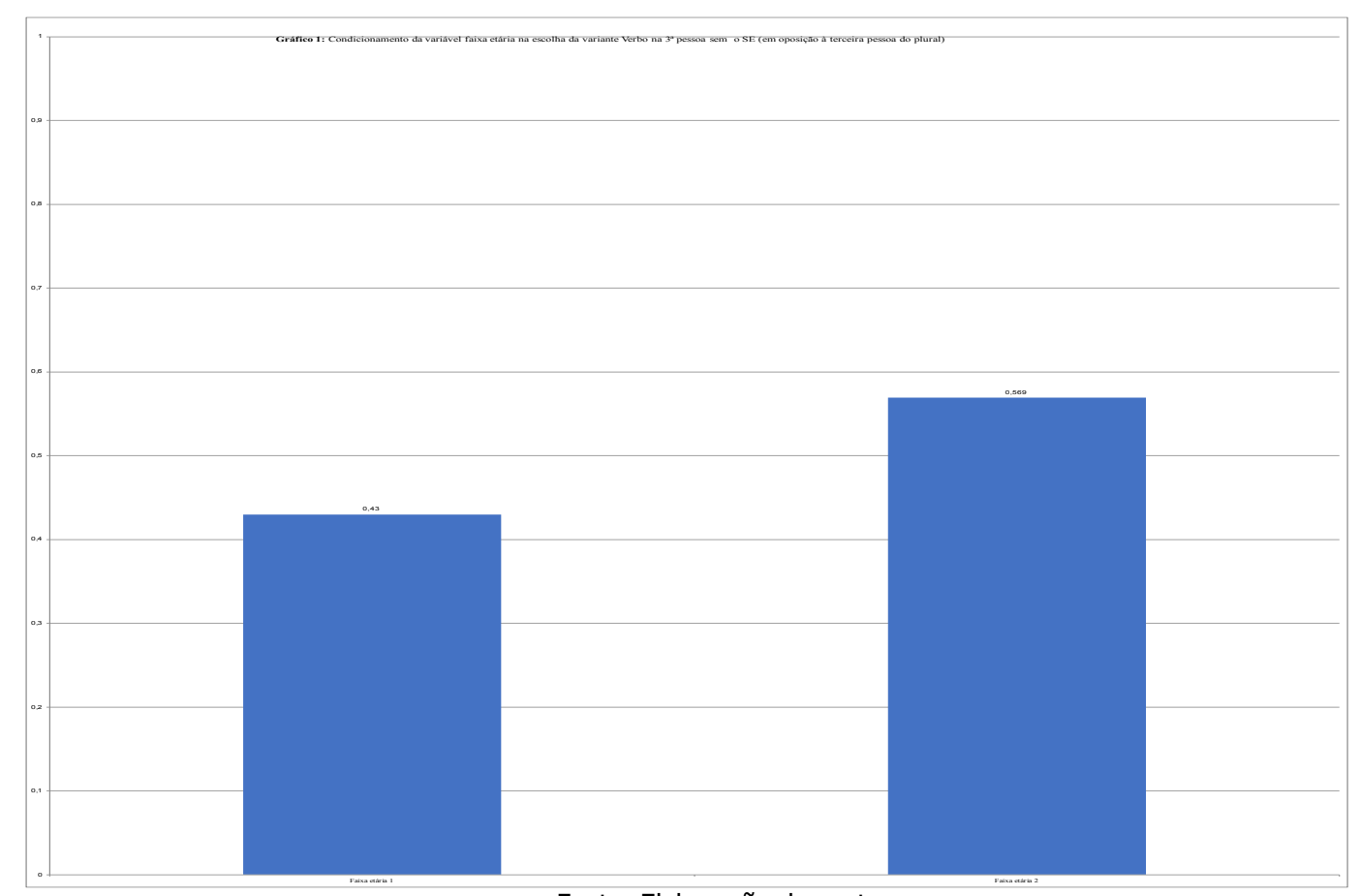

Fonte: Elaboração das autoras

Esse resultado pode ser considerado um indício de mudança, o que poderia levar ao desaparecimento da estrutura $3^{a}$ pessoa do singular sem o SE como variante de indeterminação. Mas essa hipótese só poderá ser conferida em fase posterior, com análise em tempo real, com o confronto com dados de uma fase futura.

A seção seguinte faz considerações em relação às formas pronominais de indeterminação do sujeito.

\section{Análise das formas pronominais de indeterminação do sujeito}

As formas pronominais de indeterminação observadas apresentaram 143 dados de um total de 403 dados. Dentre essas formas, como demonstra a tabela 3, a mais recorrente foi o a gente, com um índice de 62,9\% (90/143). 0 nós indeterminado ocorreu em 27,3\% (39/143) e o você, 9,8\% (14/143\%). 
Tabela 3: Frequência das Formas Pronominais de Indeterminação na posição de sujeito nas mesorregiões baianas.

\begin{tabular}{c|c|c}
\hline Variante & Total de Ocorrências & Percentual \\
\hline A gente & $90 / 143$ & 62,9 \\
\hline Nós & $39 / 143$ & 27,3 \\
\hline Você & $14 / 143$ & 9,8 \\
\hline Total & 143 & $100 \%$ \\
\hline
\end{tabular}

A tabela 4 apresenta as mesorregiões com a quantidade e frequência de cada variante pronominal com valor de indeterminação.

Tabela 4: Número e frequência de Formas Pronominais em cada mesorregião baiana

\begin{tabular}{l|r|c|c}
\multicolumn{2}{c}{ Tabela 4: Número e frequência de Formas Pronominais em cada mesorregião baiana } \\
\hline Cidades/Mesorregiões & A gente & Nós & Você \\
\hline Salvador/ Região Metropolitana & $7 / 13 \quad 53,8 \%$ & - & - \\
\hline Alagoinhas/ Nordeste Baiano & $34 / 59 \quad 57,6 \%$ & $25 / 5942,4 \%$ & - \\
\hline Barra/ Vale São-Franciscano da Bahia & $16 / 20 \quad 80 \%$ & $3 / 20 \quad 5 \%$ & $6 / 1346,2 \%$ \\
\hline Barreiras Extremo Oeste Baiano & $4 / 11 \quad 36,4 \%$ & $6 / 11 \quad 54,5 \%$ & - \\
\hline Ilhéus/ Sul Baiano & $1 / 1 \quad 100 \%$ & - & $1 / 205 \%$ \\
\hline Irecê/ Centro-Norte Baiano & $23 / 28 \quad 82,1 \%$ & & $1 / 11,1 \%$ \\
\hline Vitória da Conquista/Centro-Sul Baiano & $5 / 11 \quad 45,5 \%$ & $5 / 11 \quad 45,5 \%$ & \\
\hline
\end{tabular}

Conforme se vê na tabela 4, a forma a gente foi a única das três registrada em todas as mesorregiões, o nós ocorreu apenas em quatro das sete mesorregiões $\mathrm{O}$ a gente foi a que teve nas mesorregiões o maior percentual, exceto na cidade de Barreiras (no Extremo Oeste baiano) em que a variante nós aparece com um percentual igual a 54,5\%, enquanto sua forma concorrente a gente, apenas 36,4\% (apesar do pequeno número de dados) e o nós em cinco delas. Diante da distribuição não ortogonal (tabela 4) e do pequeno número de dados e percentuais em cada célula, neste artigo, não se pôde investir em análise multivariada com pesos relativos no estudo da variação com as variantes pronominais.

O corpus do $\mathrm{ALiB}$, por se constituir principalmente de respostas rápidas, sem grande interação entre Documentador e Informante, parece não propiciar contexto para muitas ocorrências do você e do nós indeterminado. Para o estudo do fenômeno da indeterminação do sujeito envolvendo as variantes 
nós e você, é necessário aprofundar o estudo das formas pronominais com observação de mais material de outro(s) acervo(s) para comparação e ampliação dos resultados.

A seção seguinte trata do último tipo de variantes observadas neste artigo, as formas nominais de indeterminação.

\section{Análise das formas nominais de indeterminação do sujeito}

Na observação feita sobre a indeterminação do sujeito expressa por formas nominais no estado da Bahia, levantaram-se muitos dados de sujeito indeterminado constituído de um substantivo, como pessoa, mundo, cara, turma ou pronomes indefinidos em sintagmas com estruturas sintáticas diferentes, consideradas aqui como grupos $\mathrm{A}, \mathrm{B}$ e $\mathrm{C}$, a seguir caracterizadas.

O grupo A é constituído por variante com a configuração sintática constituída por nome antecedido por um artigo. São exemplos dessas variantes:

(11) Às vezes as pessoas falam uma poça de água.

(12) Os outros falam trovão.

(13) $O$ povo chama de aleijado.

(14) $O$ pessoal quer andar é de pé, mesmo.

(15) A maioria chama de gaúcho.

(16) Os cara chama de...

(17) A turma chama sovaco.

O grupo $B$ tem um núcleo que é antecedido por um pronome indefinido, como os dados a seguir:

(18) Muita gente fala assim.

(19) Cada quem diz de um jeito.

(20) Cada qual quer puxar seu rancho.

(21) Todo mundo aqui chama assim.

As variantes do grupo C são constituídas por um único elemento, ou pronome indefinido, ou elemento substantivado com valor indefinido, a exemplo de:

(22) Fulana tá menstruada.

(23) Uns chama pinguela, outros chama ponte.

(24) já tem aqueles que usa mais pra transporte.

Dos 811 dados coletados na presente pesquisa, 265 compõem o escopo das formas nominais analisadas. Considerando os 3 grupos, de acordo com sua estrutura sintática, com o intuito de facilitar a análise, a tabela 5 revela o quantitativo de dados e percentual de cada grupo e o gráfico 3 possibilita melhor visualização da distribuição dessas variantes na totalidade das variantes nominais de indeterminação. 
Tabela 5: Distribuição dos grupos A, B e C no total de formas nominais de indeterminação nas mesorregiões baianas

\begin{tabular}{l|c|c}
\hline \multicolumn{1}{c|}{ Variantes } & Ocorrências/ Total & Percentual \\
\hline Variantes Nominais do grupo A & $148 / 265$ & $55,8 \%$ \\
\hline Variantes Nominais do grupo B & $16 / 265$ & $6 \%$ \\
\hline Variantes Nominais do grupo C & $101 / 265$ & $38,2 \%$ \\
\hline
\end{tabular}

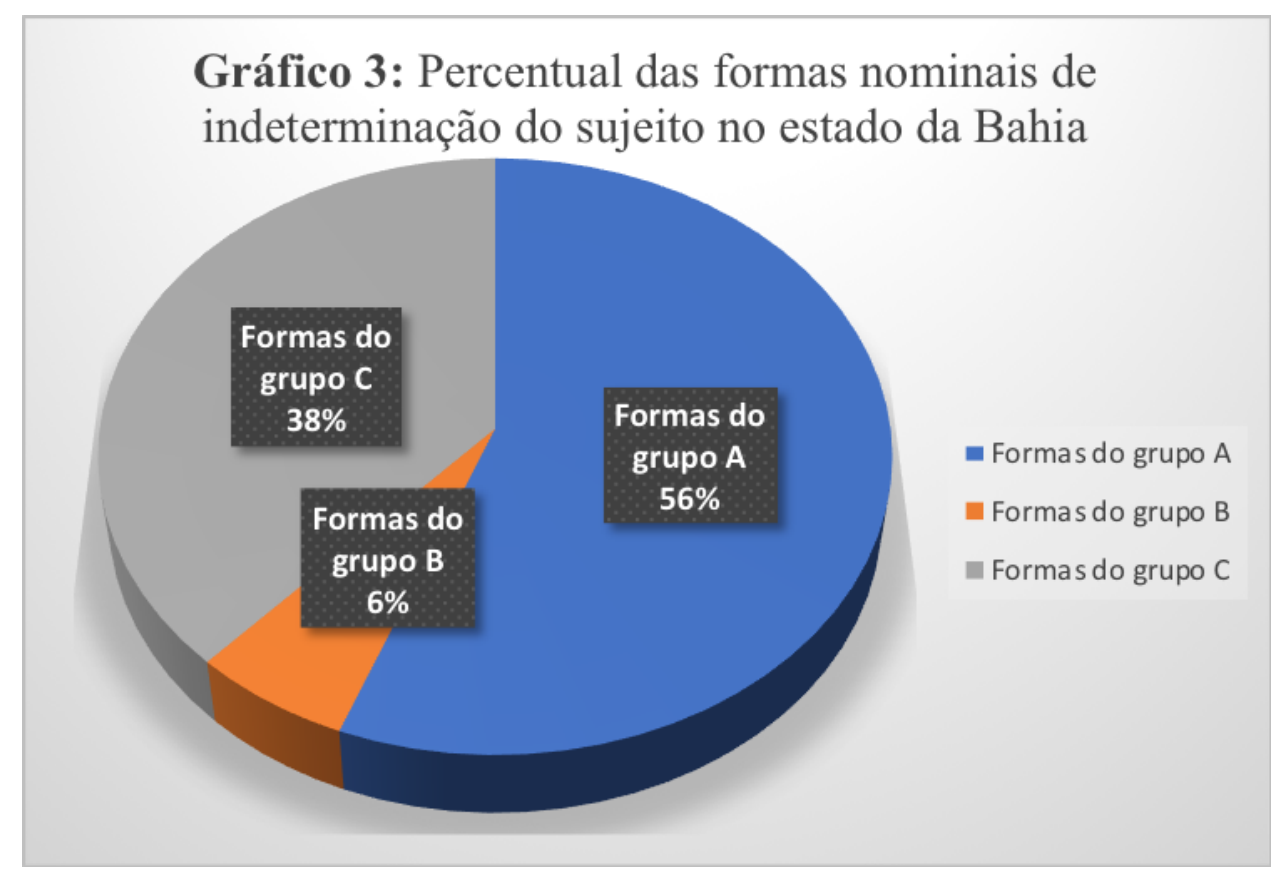

Fonte: Elaboração das autoras

Diante do pequeno índice de variantes do grupo B de variantes nominais de indeterminação, elas foram retiradas da continuidade do estudo e de seu refinamento, o que possibilitou que se chegasse à análise de regras variáveis. Assim, optou-se por considerar o Grupo A o ponto de observação.

$\mathrm{Na}$ análise de regras variáveis, através do programa GoldVarb, foram selecionadas as variáveis mesorregiões e faixa etária, a seguir tratadas.

A tabela 6 e o gráfico 4 apresentam resultados do condicionamento das mesorregiões baianas para a escolha das variantes do Grupo A.

Tabela 6: Condicionamento das mesorregiões baianas para a escolha das variantes do Grupo A.

\begin{tabular}{l|c|c|c}
\hline Cidades/Mesorregiões da Bahia & Dados A/Total & $\%$ & Peso relativo \\
\hline Salvador/Região Metropolitana (MET) & $11 / 32$ & $34,4 \%$ & 0,275 \\
\hline
\end{tabular}




\begin{tabular}{l|c|l|c}
\hline Alagoinhas/ Nordeste Baiano (NeBa) & $9 / 26$ & $34.6 \%$ & 0,269 \\
\hline Irecê/Centro-Norte Baiano (CNBa) & $17 / 34$ & $50 \%$ & 0,259 \\
\hline Ilhéus/ Sul Baiano (SBa) & $30 / 44$ & $68,2 \%$ & 0.403 \\
\hline Barra/ Vale São-Franciscano da Bahia (VSFBa) & $27 / 41$ & $65,9 \%$ & 0,565 \\
\hline Barreiras/ Extremo Oeste Baiano (EOeBa) & $19 / 27$ & $70,4 \%$ & 0,761 \\
\hline Vitória da Conquista/ Centro-Sul Baiano (CSBa) & $35 / 45$ & $77,8 \%$ & 0,820 \\
\hline
\end{tabular}

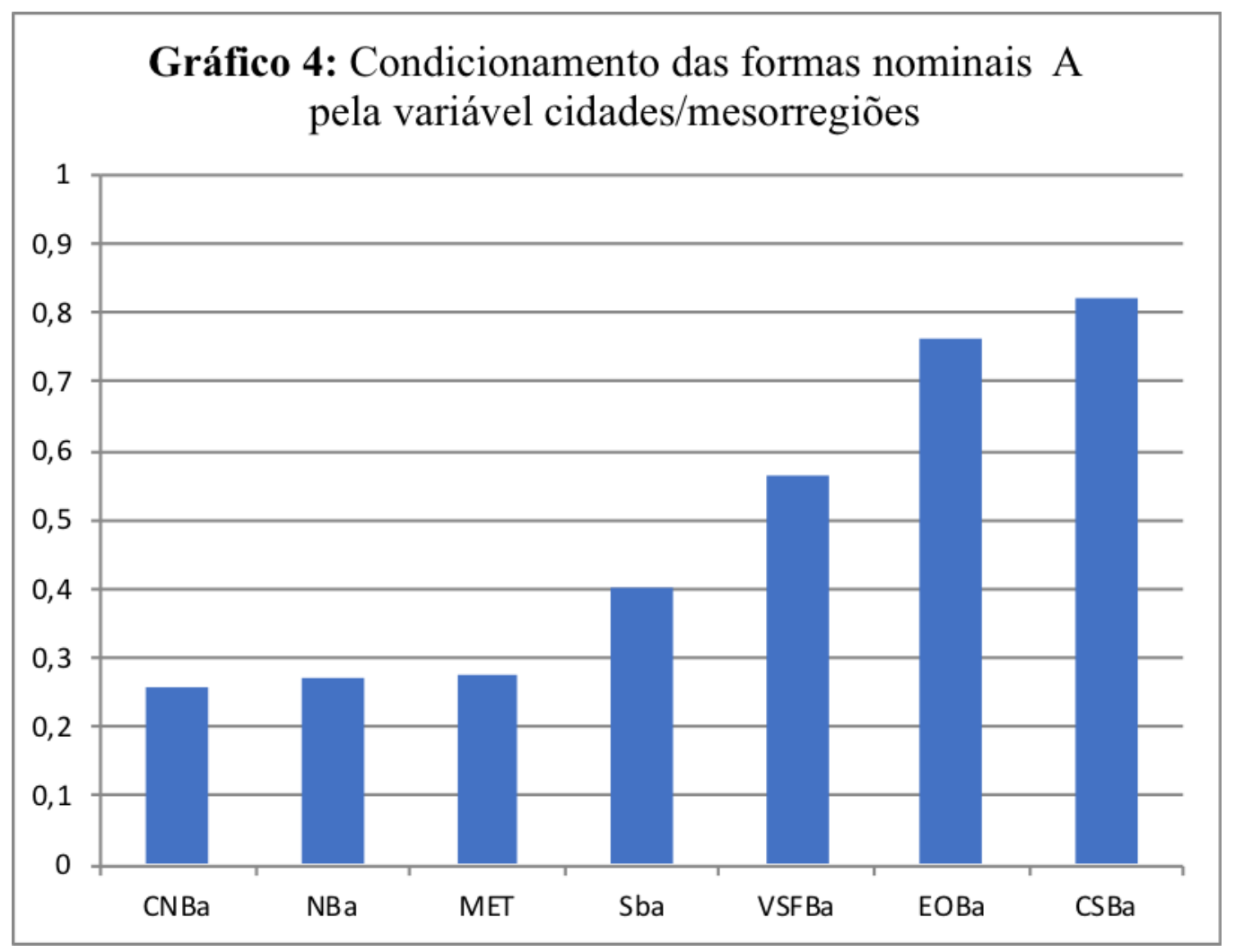

Os resultados revelam que a variante formas nominais $A$ é favorecida principalmente em Vitória da Conquista - Centro-Sul Baiano (CSBa) e Barreiras (Extremo-Oeste baiano) e, muito levemente, em Barra, no Vale São-Franciscano da Bahia (VSFBa). Ao lado disso, é desfavorecida nos demais municípios/mesorregiões estudados. O gráfico 4 mostra um crescente da variante Formas Nominais $A$, que vai do Centro Norte Baiano, passa pelo Nordeste Baiano, pela Região Metropolitana, reduz um pouco o desfavorecimento na região Sul Baiana, chega a favorecer a partir da região do Vale São Franciscano da Bahia e amplia ainda mais esse favorecimento no Extremo Oeste Baiano, atingindo o maior peso na região do Centro Sul Baiano, em Vitória da Conquista. A figura 2 ilustra esses resultados. 
Figura 2: Mapeamento das Cidades/Mesorregiões que favorecerem as variantes nominais de indeterminação dos Grupos A ou C.

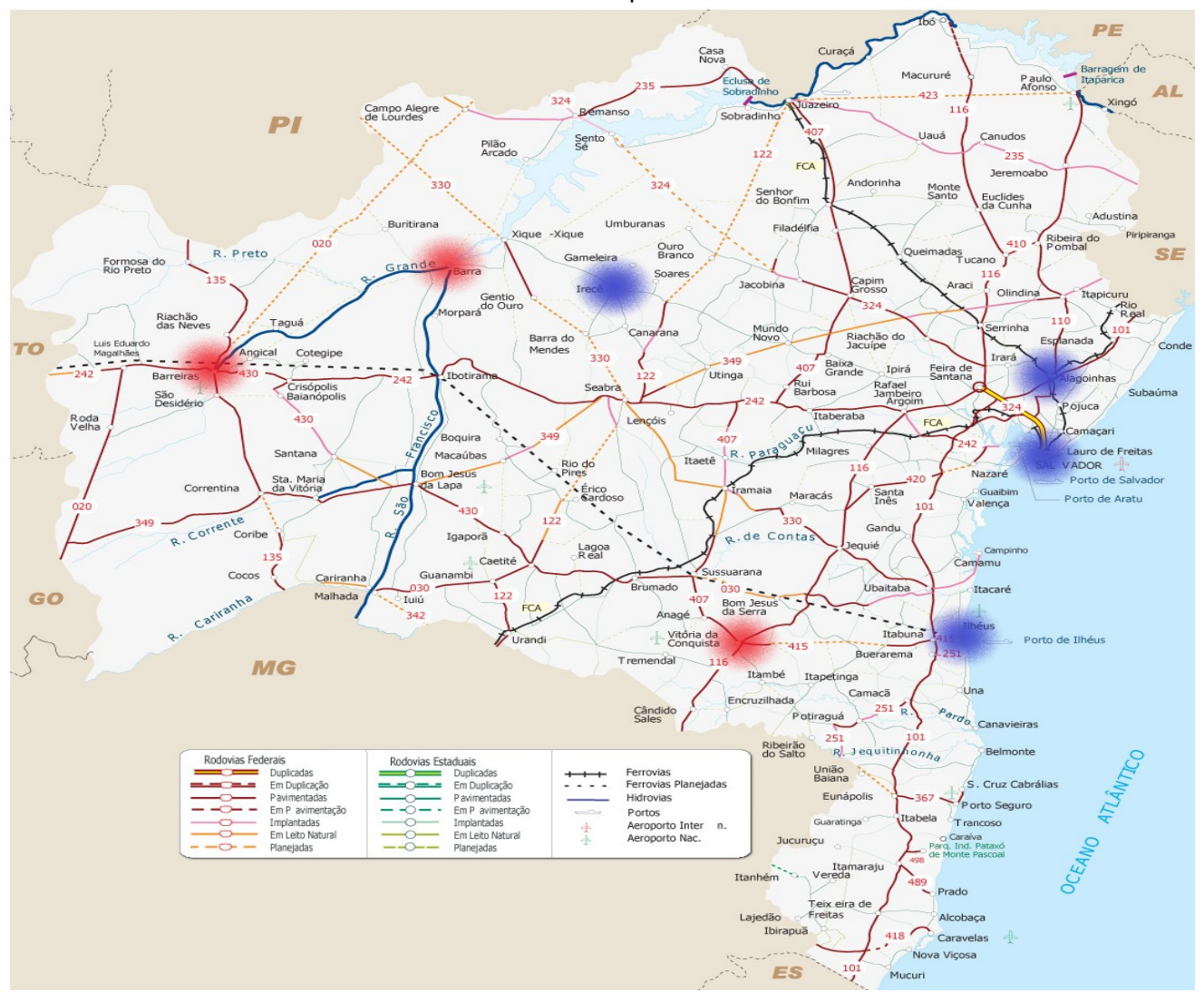

Legenda: vermelho - favorecimento do grupo A; azul - desfavorecimento do grupo A. Fonte: www.google.com (mapa modificado por GUIMARÃES, 2018)

A segunda variável selecionada pelo programa GoldVarb foi a faixa etária. A tabela 7 apresenta os resultados da análise.

Tabela 7: Condicionamento da Faixa etária sobre a escolha das variantes nominais de indeterminação do Grupo A nas

\begin{tabular}{l|c|c|c}
\multicolumn{2}{c}{ mesorregiões baianas. } & \% & Peso relativo \\
\hline Variável & Dados A/Total & $87,2 \%$ & 0,872 \\
\hline Faixa etária 1 & $68 / 78$ & $46.8 \%$ & 0,294 \\
\hline
\end{tabular}

Fonte: Guimarães (2018)

O gráfico 5 permite melhor visualização desses resultados. 
Gráfico 5 - Condicionamento da Faixa etária sobre a escolha das variantes nominais de indeterminação do Grupo A nas mesorregiões baianas.

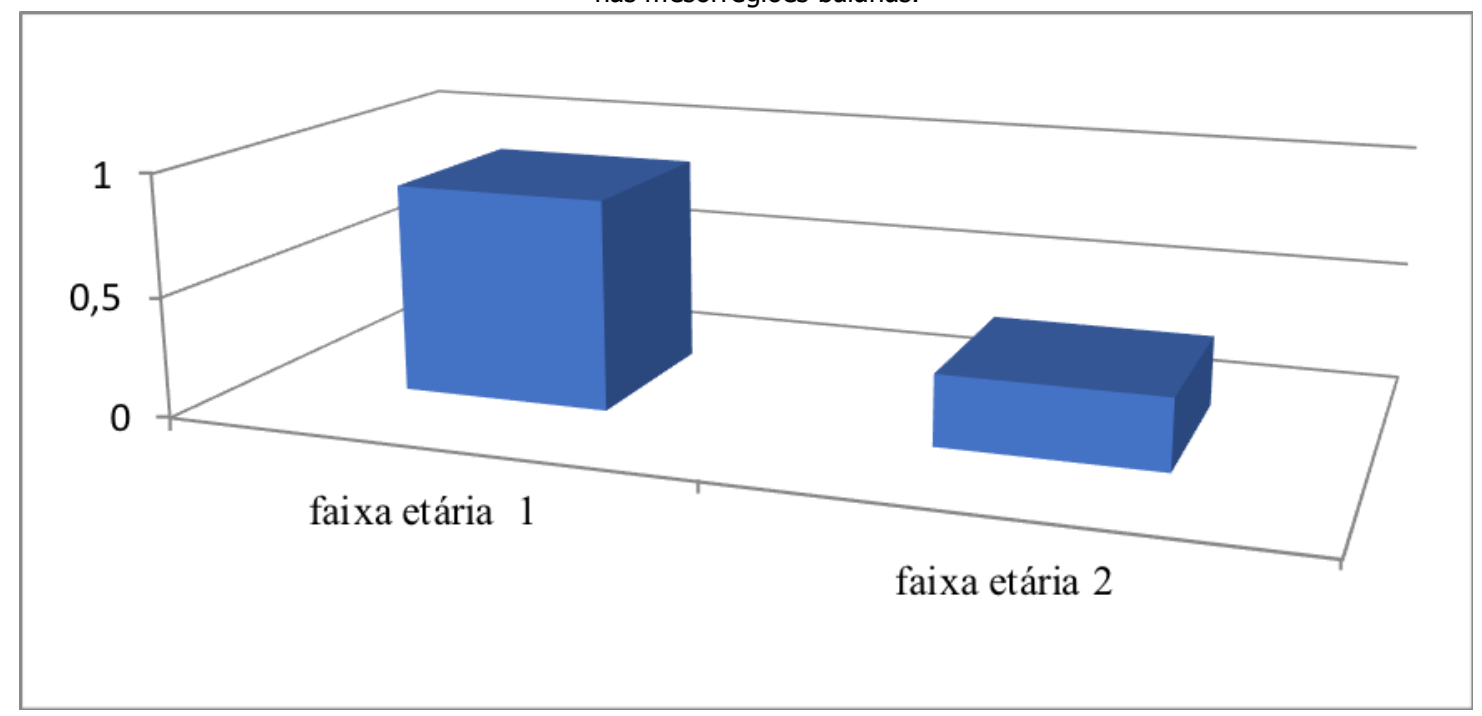

Fonte: Guimarães (2018)

Os resultados da análise do condicionamento da faixa etária sobre a escolha da variante nominal de indeterminação indicaram que os falantes mais jovens têm uma tendência ao uso das variantes do tipo A, e os mais velhos tendem a realização de formas do grupo C. Esse dado nos leva à ideia de que as variantes do tipo $\mathrm{C}$ podem estar caminhando para o desaparecimento.

\section{A indeterminação do sujeito e o ensino}

Resta refletir como o estudo empreendido pode contribuir para a melhoria do ensino, na educação básica. Diante do conhecimento dos resultados, deve haver, por parte da escola,

- $\quad$ consciência da real diversidade na forma de indeterminação do sujeito;

- respeito às diversas formas de indeterminação;

- aceitação das diferentes formas de indeterminação do sujeito

- apresentação das formas conservadoras, presentes na modalidade escrita da língua, principal foco da atividade escolar, como possibilidades mais recorrentes em textos escritos;

- $\quad$ busca constante de novas formas, ainda não registradas que carreguem valor de indeterminação;

- mudança na postura de estudo de questões estruturais da língua, na escola, em que haja observação de dados, com menos prescrição, e mais descrição.

\section{Considerações finais}

O presente artigo tratou da variação em formas de indeterminação do sujeito nas mesorregiões baianas. As formas de indeterminação estudadas na presente pesquisa (gramaticais, pronominais e 
nominais) são utilizadas em todas as mesorregiões analisadas. Os dados percentuais revelaram que as formas gramaticais aparecem em primeiro lugar, seguidas respectivamente das formas nominais e pronominais.

A análise de regras variáveis das formas pronominais não foi feita, diante do número reduzido de dados, mas cabe ressaltar que a principal estratégia pronominal de indeterminação em níveis percentuais foi a variante a gente $(62,9 \%)$. Isso aconteceu em quase todas as cidades/mesorregiões, exceto na cidade de Barreiras (no Extremo Oeste baiano) em que a variante nós aparece com um percentual igual a $54,5 \%$, enquanto sua forma concorrente a gente, apenas com $36,4 \%$.

A análise das formas nominais revelou que o grupo mais utilizado foi o grupo A (artigo+substantivo/pronome), por isso submetido ao programa juntamente com sua forma concorrente (grupo C).

O GoldVarb selecionou as variáveis cidades/mesorregiões' e faixa etária como fatores que condicionaram o uso das variantes do grupo $\mathrm{A}$. Na análise da variável 'cidades/mesorregiões', três delas (Vitória da Conquista, Barreiras e Barra) se distinguiram das demais, pois demonstraram favorecer as formas nominais do grupo $A$ (as pessoas, os outros, o povo, o pessoal, a maioria, os cara (s) e a turma).

$\mathrm{Na}$ análise da faixa etária, a pesquisa mostra que os jovens tendem a usar as variantes do grupo A mais que os mais velhos, que as desfavorecem. Há, dessa forma, uma indicação de que formas de indeterminação do grupo $\mathrm{C}$ (usadas pela faixa etária 2 ) tendem ao desaparecimento.

Trabalhos futuros deverão confirmar ou não as tendências de mudança percebidas entre as variantes gramaticais e as variantes nominais de indeterminação levantadas no corpus estudado nas cidades/mesorregiões da Bahia aqui observadas.

A atividade escolar deve demonstrar conhecimento dos usos reais de formas de indeterminação, evidenciando respeito à diversidade. A escola, apesar disso, não pode perder de vista, a necessidade de possibilitar aos seus alunos a apropriação de usos mais formais e mais relacionados à modalidade escrita, ampliando, assim, as suas possibilidades de produzir e le textos em língua portuguesa.

\section{Referências}

CARDOSO, Suzana Alice Marcelino da Silva et al. Atlas linguístico do Brasil. Londrina: EDUEL, 2014.

CUNHA, C. F.; CINTRA, L. Nova gramática do Português contemporâneo. Rio de Janeiro: Nova Fronteira, 1985.

GUIMARÃES, Tassila Ferreira Vale. Formas de indeterminação do sujeito no estado da Bahia: um estudo geo-sociolinguístico. Salvador: Universidade do Estado da Bahia. Programa de Pós-Graduação em Estudo de Linguagens, 2018. (Dissertação de Mestrado)

NEVES, Maria Helena de Moura. Gramática de usos do português. São Paulo: Editora UNESP, 2000.

PERINI, Mário A. Gramática do português brasileiro. São Paulo: Parábola Editorial, 2010.

ROCHA LIMA, Carlos H. da. Gramática normativa da língua portuguesa. Rio de Janeiro: José Olympio, 1985 


\section{Sites relacionados}

Baixar mapas: mapas geográficos, seção Bahia, estados. Disponível em: http://www.baixarmapas.com.br/mapa-da-bahia-mesorregioes. Acesso em: 14 fev. 2018. Google images. Disponível em: < www.google.com>. Acesso em: 29 jul. 2017.

Site do IBGE. Disponível em: <www.ibge.gov.br>. Acesso em: 18 jul. 2017. 